\title{
Multiple Clustered Dermatofibromas Following Ustekinumab Treatment for Psoriasis Vulgaris
}

*Ricardo Ruiz-Villaverde, ${ }^{1}$ Miguel A. Díaz-Martinez, ${ }^{1}$ Daniel Sánchez-Cano ${ }^{2}$

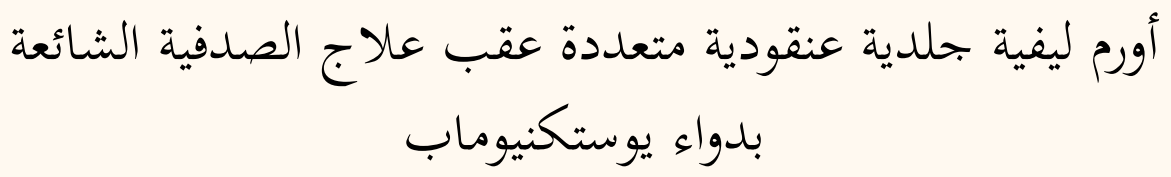

ريكاردو رويز-فيلافيردي، مقويل أنطونيو دياز-مارتنيز، دانيل سانشيز-كانو

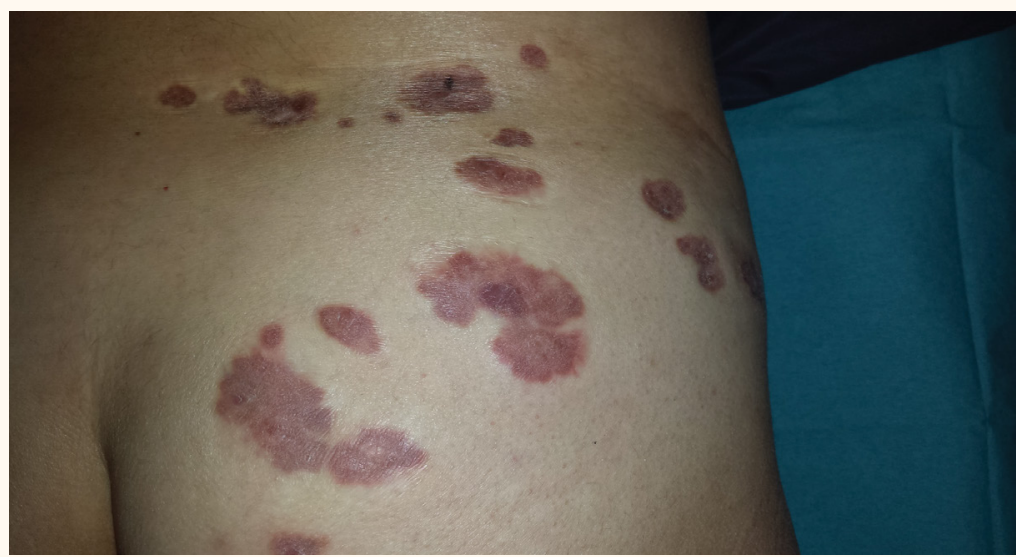

Figure 1: Photograph of multiple clustered purple-brown plaques in the right gluteal region of a 24-year-old man with psoriasis vulgaris.

A 24-YEAR-OLD MAN WITH A SIX-YEAR history of psoriasis vulgaris was referred to the dermatological outpatient clinic of the Complejo Hospitalario de Granada, Granada, Spain, in 2016 with multiple brownish cutaneous lesions of different sizes in the right gluteal region. No previous injuries, comorbid conditions or use of concomitant medications were reported. The patient had been undergoing treatment for psoriasis vulgaris with $45 \mathrm{mg}$ of ustekinumab every three months over the previous eight months after other methods of treatment had failed, including methotrexate, cyclosporine and narrowband ultraviolet B phototherapy. The ustekinumab treatment had since resulted in good control of the psoriasis vulgaris (Psoriasis Area and Severity Index score: 0.8 ; body surface area: 1 ; Physician Global Assessment score: 1). However, the gluteal lesions had begun to appear one month after ustekinumab treatment was initiated.

A physical examination revealed a total of 17 hyperpigmented nodules and plaques grouped within the right gluteal area ranging from $0.3-2.4 \mathrm{~cm}$ in size [Figure 1]. A polarised dermoscopy using the DermLite III Dermascope (3Gen LLC, San Juan Capistrano, California, USA) revealed a peripheral delicate pigment network and white scar-like patch [Figure 2]. A histological examination of a punch biopsy of one of the lesions showed acanthosis and hyperpigmentation of the basal keratinocytes on the epidermis with fibroblastic proliferation without atypia on the reticular dermis [Figure 3A]. An immunohistochemical study indicated positivity to vimentin and factor XIIIa and negativity to $\mathrm{S} 100$ and cluster of differentiation (CD)34 [Figures 3B and C]. These findings excluded a diagnosis of dermatofibrosarcoma protuberans and confirmed a diagnosis of multiple dermatofibromas.

Routine laboratory investigations, including a complete blood count and general biochemistry, HIV, hepatitis $\mathrm{B}$, hepatitis $\mathrm{C}$, autoimmune and thyroid tests, were within normal limits. Serological tests were negative for rheumatoid factor and antinuclear antibodies. A purified protein derivative test and 


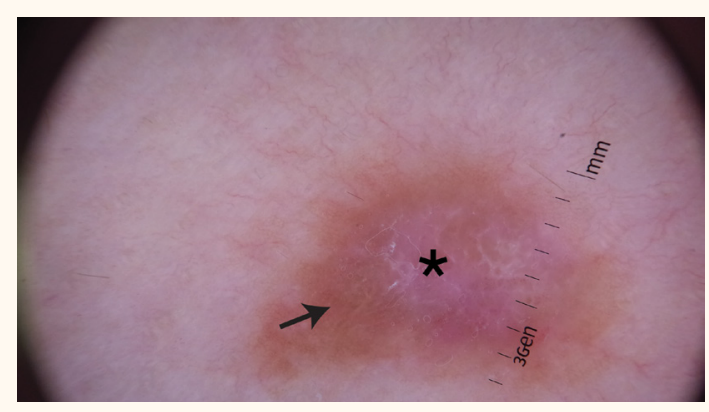

Figure 2: Dermoscopy image at x10 magnification showing a peripheral delicate pigment network (arrow) and white scarlike patch (asterisk).

radiography of the thorax also indicated no anomalies. With the patient's consent, the decision was made to continue ustekinumab treatment. As the patient refused any surgical or medical treatment, the lesions persisted.

\section{Comment}

Multiple dermatofibromas are defined as the appearance of at least 15 dermatofibromas in less than a year or 5-8 dermatofibromas within four months. ${ }^{1}$ Dupré et al. first used the term 'clustered' in 1984 to refer to the grouping of these lesions in a segmental distribution. $^{2}$ To date, very few cases of multiple clustered dermatofibromas have been reported in the literature. $^{3}$ The individual lesions of multiple dermatofibromas are not clinically, histologically or phenotypically different from that of a solitary dermatofibroma. ${ }^{3}$

Multiple clustered dermatofibromas have not been found to be associated with any underlying malignancies, immunosupression, previous trauma or other comorbidities. ${ }^{4}$ Viseux et al. reported a kidney transplant patient who had developed multiple clustered dermatofibromas over the pathway of thrombosed superficial veins. ${ }^{5}$ Although a congenital case has been reported, the age of onset for most patients with multiple clustered dermatofibromas is between the first and third decade of life. ${ }^{6,7}$ No reports of metastasis or malignancy have been described so far, even with follow-up periods of up to 20 years. ${ }^{7}$

In the present case, with regards to the role of ustekinumab, causation cannot be proven; however, a similar case has been described with the biological drug efalizumab. ${ }^{8}$ Moreover, the development of multiple eruptive dermatofibromas in immunomodulated situations could be explained by the inhibition of downregulatory T cells..$^{8-10}$ Systemic lupus erythematosus is the most common underlying disease associated with multiple eruptive dermatofibromas. ${ }^{9}$ However, it is important to note that the degree of immunosuppression does not seem to correlate with the number of dermatofibromas. ${ }^{11}$

Histologically, the differential diagnosis for multiple clustered dermatofibromas includes dermatofibrosarcomas protuberans, dermatomyofibromas, leiomyomas and, in paediatric cases, plaque-like myofibroblastic tumours. Immunostaining with CD34 may be helpful in confirming the diagnosis. ${ }^{12}$ Clinically, the lesions may mimic atypical fibroxanthomas, nodular fasciitis and dermatofibrosis lenticularis disseminata. ${ }^{13}$ From a therapeutic point of view, a conservative approach is advisable. Techniques used with varying success include cryotherapy, intralesional steroids, surgery and phototherapy. ${ }^{13,14}$

\section{References}

1. Baraf CS, Shapiro L. Multiple histiocytomas: Report of a case. Arch Dermatol 1970; 101:588-90. doi: 10.1001/arch derm.1970.04000050092013.

2. Dupré A, Christol B, Martinez D. [Multiple clustered histiocytofibroma]. Ann Dermatol Venereol 1984; 111:163-4.

3. Gershtenson PC, Krunic AL, Chen HM. Multiple clustered dermatofibroma: Case report and review of the literature. J Cutan Pathol 2010; 37:e42-5. doi: 10.1111/j.1600-0560.2009. 01325.x
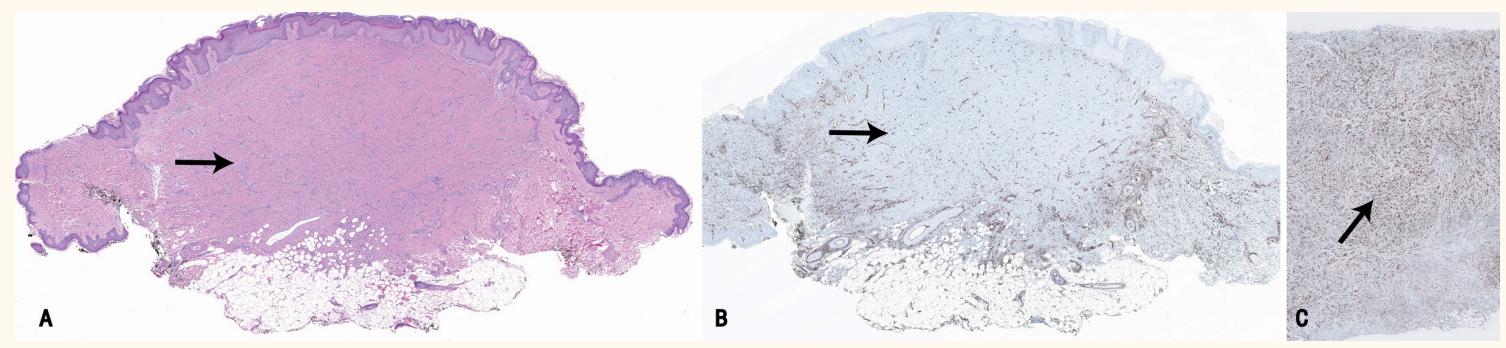

Figure 3: A: Haematoxylin and eosin stain of a punch biopsy at $x 2$ magnification showing a proliferation of spindle cells (arrow) in the dermis and subcutaneous tissue. B: Immunohistochemistry stain at $x 4$ magnification showing cells negative for cluster of differentiation (CD)34 (arrow). C: Immunohistochemistry stain at x10 magnification showing cells positive for factor XIII (arrow). 
4. Bhabha FK, Magee J, Ng SY, Grills CE, Su J, Orchard D. Multiple clustered dermatofibroma presenting in a segmental distribution. Australas J Dermatol 2016; 57:e20-2. doi: 10.1111/ ajd.12257.

5. Viseux V, Chaby G, Agbalika F, Luong MS, Chatelain D, Westeel PF, et al. Multiple clustered dermatofibromas on a superficial venous thrombosis in a kidney-transplanted patient. Dermatology 2004; 209:156-7. doi: 10.1159/000079603.

6. De Unamuno P, Carames Y, Fernandez-Lopez E, HernandezMartin A, Peña C. Congenital multiple clustered dermatofibroma. Br J Dermatol 2000; 142:1040-3. doi: 10.1046/j.13652133.2000.03494.x

7. Castellanos-González M, Rodríguez-Peralto JL, Zarco C, OrtízRomero P. [Multiple clustered dermatofibromas: An atypical presentation of a common disease]. Actas Dermosifiliogr 2011; 102:467-8. doi: 10.1016/j.ad.2010.12.003.

8. Santos-Juanes J, Coto-Segura P, Mallo S, Galache C, Soto J. Multiple eruptive dermatofibromas in a patient receiving efalizumab. Dermatology 2008; 216:363. doi: 10.1159/000 117708

9. Caldarola G, Bisceglia M, Pellicano R. Multiple eruptive plaque-like dermatofibromas during anti-TNF $\alpha$ treatment. Int J Dermatol 2013; 52:638-41. doi: 10.1111/j.1365-4632.20 11.05047.x.
10. Zaccaria E, Rebora A, Rongioletti F. Multiple eruptive dermatofibromas and immunosuppression: Report of two cases and review of the literature. Int J Dermatol 2008; 47:723-7. doi: 10.1111/j.1365-4632.2008.03575.x.

11. Goldbach H, Wanat K, Rosenbach M. Multiple eruptive dermatofibromas in a patient with sarcoidosis. Cutis 2016; 98:E15-19.

12. Reynolds H, Perry A, Satter EK. Multiple clustered and focally atrophic dermatofibromas (DF). Dermatol Online J 2014; 20:22612.

13. Shaheen B, Saldanha G, Calonje E, Johnston GA. Multiple clustered dermatofibromas (fibrous histiocytomas): An atypical clinical variant of dermatofibroma. Clin Exp Dermatol 2014; 39:88-90. doi: 10.1111/ced.12200.

14. Soloeta R, Yanguas I, Saracíbar N, Goday JJ. [Multiple clustered histiocytofibroma: Apropos of a case with immunohistochemical study]. Ann Dermatol Venereol 1994; 121:482-4. 